\title{
The Relationship between Teams' Productivity in FTF \& CMC with factors affecting during the implementation stage
}

\author{
${ }^{1}$ Assist . Prof. Dr. Wadhah A. Hatem \\ Baquba Technical Institute/ Diyala/ Iraq ,E-mail: wadhah1970wadhah@gmail.com \\ ${ }^{2}$ Assist . Prof. Dr. Hafadh I. Naji \\ Civil Engineering Department, University of Diyala /Iraq, E-mail:hafizibrahem1973@gmail.com \\ ${ }^{3}$ Zainab A. Abd Alkreem \\ Student in Civil engineering, E-mail: zainabeng63@yahoo.com
}

\begin{abstract}
:
Productivity is one of the major objectives in team working, and among others aim as efficiency, quality, etc. It is a mean to success in any business. Many of previous studies compare between team productivity in Face To Face communication (FTF) and Computer -mediate Communication (CMC) without considerate factors effects on this productivity which related with partners behavior and manners. This paper studies the correlation between these factors and team productivity in both methods of communication styles. The methodology adopted in this research is the experimental work to measure team productivity into methods during the execution phase. The results show a strong correlation factor between team productivity and total number of work related words in both FTF and $\mathrm{CMC}$ for each time interval and this relation was negative in FTF and positive in CMC for 16 experiments. For number of exchanges which consider as a measure of the collaboration degree between team work, the correlation was strong between productivity and number of exchange in both communication techniques. Finally, team productivity was a negative relationship with wasted time and positive with working time.
\end{abstract}

Keywords: Team, Productivity, FTF, CMC

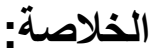

الانتاجية أحد الاهداف الرئيسية في عمل الفريق مع أهداف اخرى مثل الكفاءة والجودة الخ، وهي وسيلة

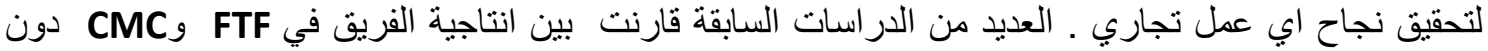

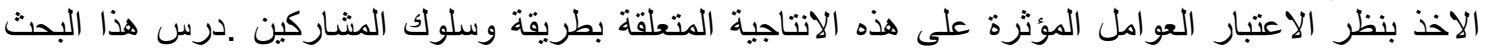

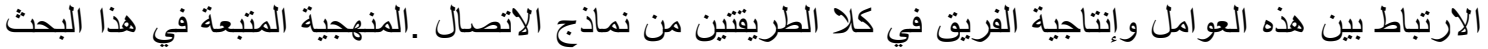

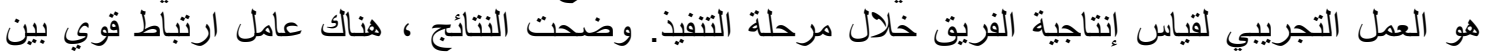

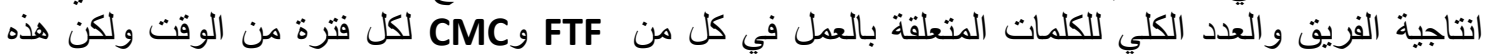

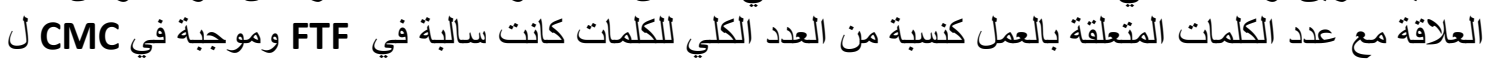

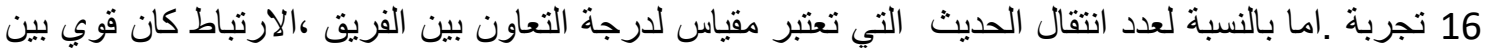

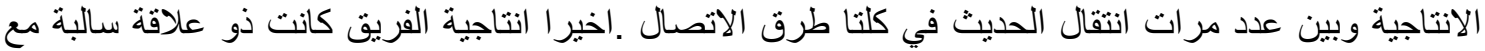
الوقت الضائع و علاقة موجبة مع وقت العمل .

الكلمات الافتتاحية :الفريق ، الاتتاجية ،طرق الاتصال FTF و 


\section{Introduction}

We live in an increasingly collaborative world, a communication technology, multinational businesses, and a global interaction, team membership and collaboration have become a critical element of success [1]. Collaborative working depends heavily on the effectiveness of information management and communication in the project life cycle. Construction productivity is affected by many factors which, when not handled properly can cause great productivity loss. In order to maintain adequate productivity standards, construction firms should track the main causes of productivity loss and work towards a method for controlling them to improve construction productivity and performance [2]. Communication between team members one of the factors effect on team productivity in two methods FTF and CMC. Construction productivity can be boosted using of information technology and have enable project participants to collect and share important field data in a timely and accurate manner [3]. This paper aims to a better understanding of the issues relating to information flow management using centralized platforms .It will allow us to illustrate the degree of usefulness and practicality of using BIM (Building Information Modeling) as techniques and processes which are considered the best solution for poor information management processes within the network construction project. Also, in this paper, the researcher will illustrate the correlation rate between communication's parameter and team productivity whether to increase or decrease.

\section{Related Works}

This section explains role of team work in construction industry, team work productivity, working time and wasted time and finally deals with the two method of communication (FTF) and (CMC) which used in this paper.

\subsection{Team in the Construction Industry}

Several researches have defined the term 'construction project team' in various ways. According to Chan and Tam [4], a project team in the construction industry is a group of construction professionals and personnel from one or more organizations who combine to fulfill the necessary design, detailing and construction functions comprising the construction project. Lawler et al. [5] stated that 60 as a percent of the 313 firms increase of utilizing of teams during the next centuries. Only 3 as a percent of firms decide to stop the utilizing of teams. As well as, 85 as a percent of firms with 100 or more worker use some sort of work teams [6]. One survey resulted that 91 as a percent of managers approbate with the statement "teams are vital to organizational success" [7].One of the major features of using the concept of a team increases the understanding base and knowledge among member of the team . Project teams who consist of members in different degrees of experience and skills to work with each other to progress more chooses any one individual could do alone. This improves the ability 
of the team to the problem-solving by encouraging everyone to engage in finding solutions [8].

The efficiency of a team depends on many factors, from including type of communication technology used and the methods of exchange information to others. Furthermore, it depends on the types of relationships among the members [9].

\subsection{Team Productivity}

Teams' Productivity is established by individual effort named task work and gathering this effort named team work [10]. In more detail, task work may be explained as "the individual contributions to members of team that required perception the kind the task; how to trace suitable ways \& rules and how to behave with equipment" [10] . The outputs of a work- team rely on its mission; its process and its available resources [11].

- This mission can comprise an action or set of actions, a project or report and a decision or recommendation.

-The team's process consist of actions which are taken by individuals to convert their resources into services and products

- The team's resources comprise the human, materials, capital, information, social, time, money and energy existing for finishing a specific task [11].

\subsection{Working Time and Wasting Time}

Time is a major index of productivity in the construction industry [12]. The time which associated with the productive activities of jobs and the arrangement is called working time, this time identified during a specified reference period. Working time comprises periods of time spent in production of all goods and services and how time is organized for the performance of work, units for measuring working-time may be short, minutes or hours may be, or long, such as days, weeks or months[13] . According to study Kalsaas [14] wasted time was identified as $5 \%$ of working time, whereas it was identified amount $17 \%$ of working time in more limited and detailed study . Whereas, wasted time is defined as the time in which the skilled workers are useless, or as a wasted use of time. It is measuring the difference between the situation when the worker notices that work goes well, and situations where he feels that "we didn't bring much done today". The way skilled workers act is also particularly interesting since it can be seen as a reflection of production planning function, the project organization and production management [14]. There are two categories of wasting time; the first includes missing drawings, faulty work by others, missing materials and equipment, unavailable workplace, erroneous or missing information from manager, and other. In contrast, the second category seeks capturing extra time-use directly caused by insufficient drawings, lack of coordination and errors [`14]. 


\subsection{Communication Methods (FTF and CMC)}

There are two kinds of communication methods, traditional method which defined Face to Face (FTF), it is a dialogue that one has while being FTF with the other person. During this kind of communication, a person can hear and see the non-oral communication transfer by the transmitter and respond with feedback immediately [15]. On other hand ,modern method which defined Computer -Mediate Communication (CMC), which defined Virtual team, Virtual teams can be defined as : " Teams whose individuals are operating across locations and temporal boundaries using technology in varying degrees to accomplish an interdependent task "[16]. According to Lenders et al. [17] virtual teams are set of persons collaborating in the implementation of a specific project, they are distributed geographically and mostly temporally.

\section{Experimental Work}

- Experiments were performed on building model Cultural Center Appendix at the College of Engineering in Diyala University as show in Fig. (1).

- Sixteen Experiments implemented are used by two methods: Face-to-Face meetings and computer mediated communication (CMC) meetings

- Experiments were performed by a team of two users, users which work in FTF are the same in CMC, on the same modeling but tasks are different in FTF and CMC.

-Teams discuss the task which including solving design problems discovered by the site engineering before implementation from an architectural perspective, for example, exterior walls, interior walls, the roof , the floor, doors and windows , etc..

- In some experiments, teams are using a wide area network (WAN) to connect and in other experiments they are using local area network (LAN) and they use the programs Revit and Skype for communication.

- The use of cameras to record the work and the use of a program Camtasia to record the screen and note the changes that made on the model.

- Data were obtained by referring to the video recordings, as well as screen recordings. 


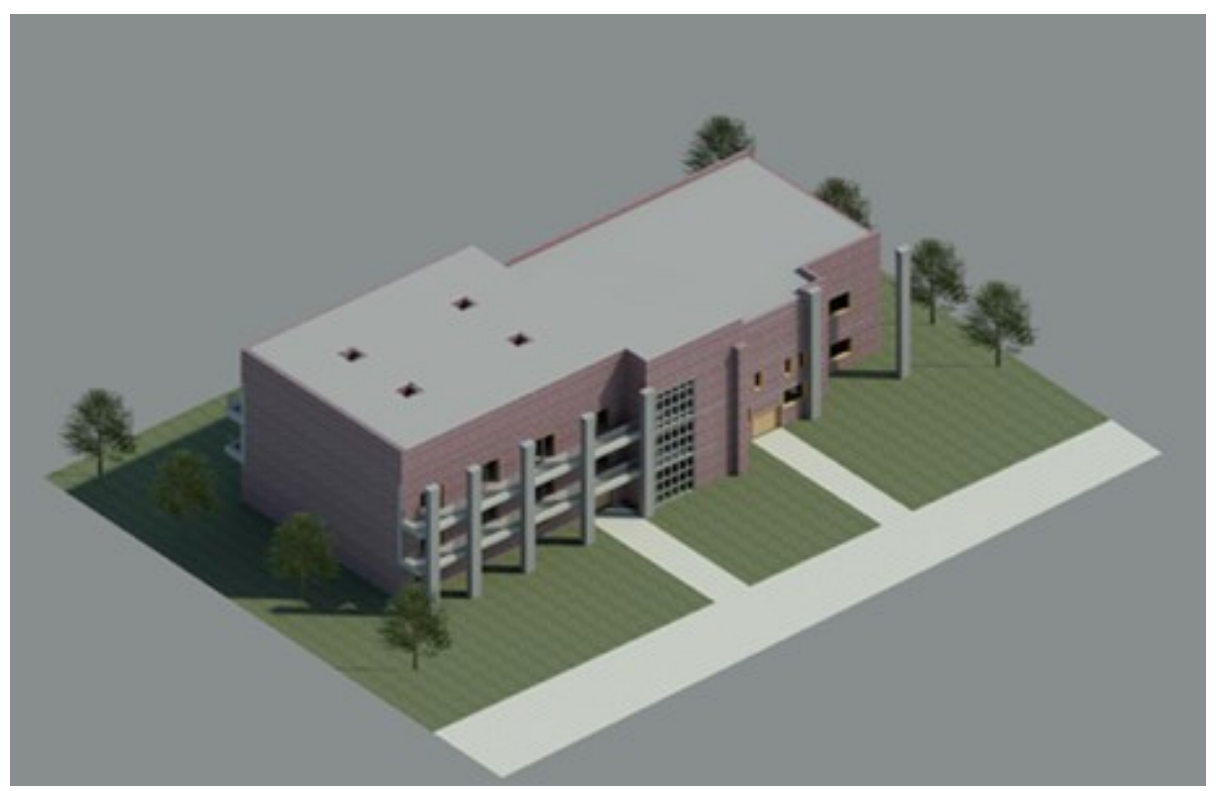

Figure (1) Culture Center Appendix model

- Analyzing the results for both FTF and CMC to extract the most important parameters, such as the number of words, work related word, working time, wasting time, the degree of collaboration and team productivity.

The approach of experiments which is structured from teams of two people, each team implemented two tasks. Task 1 is carried out by FTF team and consisted of 2 work sets (i.e. sectors): the exterior walls and doors \& windows. Task 2 is carried out by CMC team and also consisted of 2 work sets: interior wall and ceiling \& floor. It is necessary that FTF tasks should be different from CMC tasks. As previously mentioned that the team which was implemented experiment in FTF is the same in CMC in all experiments, so if the tasks in FTF and CMC were the same, the answer will be known to each user, Thus the discussion would be useless, so the tasks were designed to be in the same difficult level in both methods. To implement tasks, both users accessed to model in Revit via the same PC in FTF, while in CMC each user has special model on his computer. Work set can be established by multiple users. In this model, work set was established by two users "admin" and "Zainb" as shown in Fig. (2) Work set which consists of floors, stairs and exterior wall, all these are owned by a user called "admin" while work set which consists of col, door \& windows and interior wall, the owner of these is a user called "Zainb" this shows collaborative work in CMC experiments. 


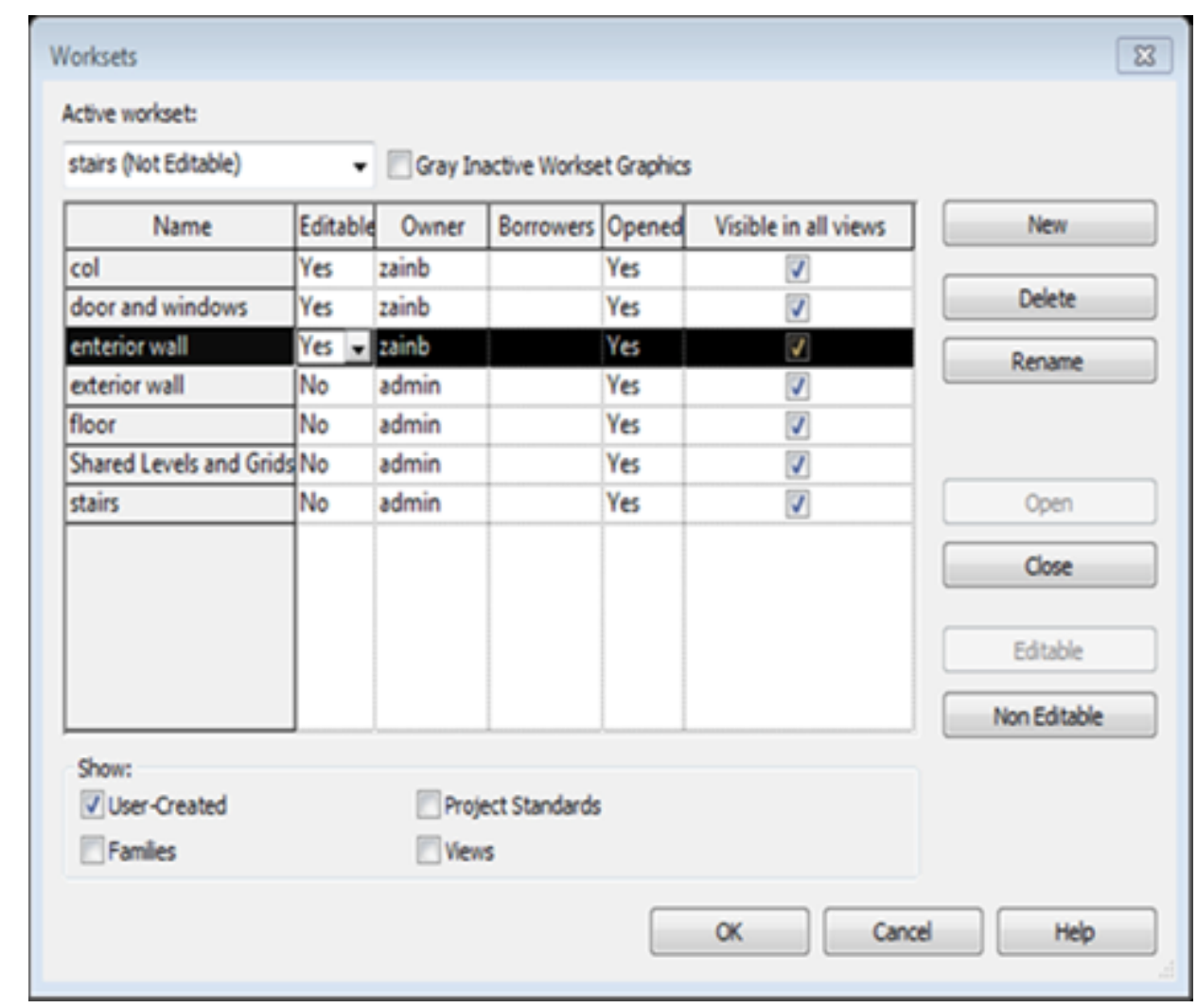

Figure (2) window of work set in Revit

In this form of collaborative work, we need to a permission request, for example, If the user "Zainb" wants to change in the exterior walls, she will be required a permission request from the user "admin" because the exterior walls are owned by user "admin" as show in Fig (3). But in most of the experiments done, work sets were owned by designer, in other word, only designer can change on the model. 


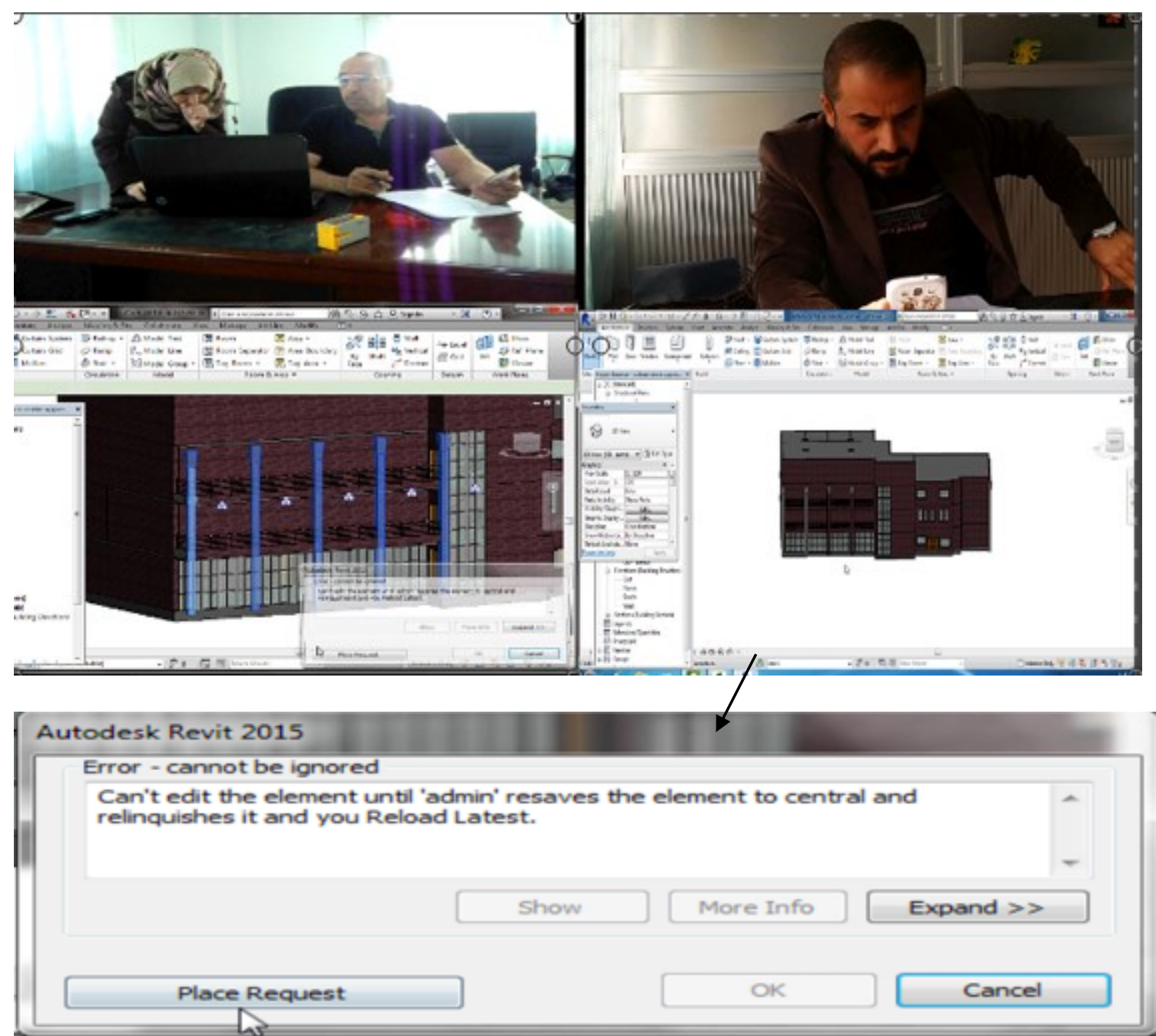




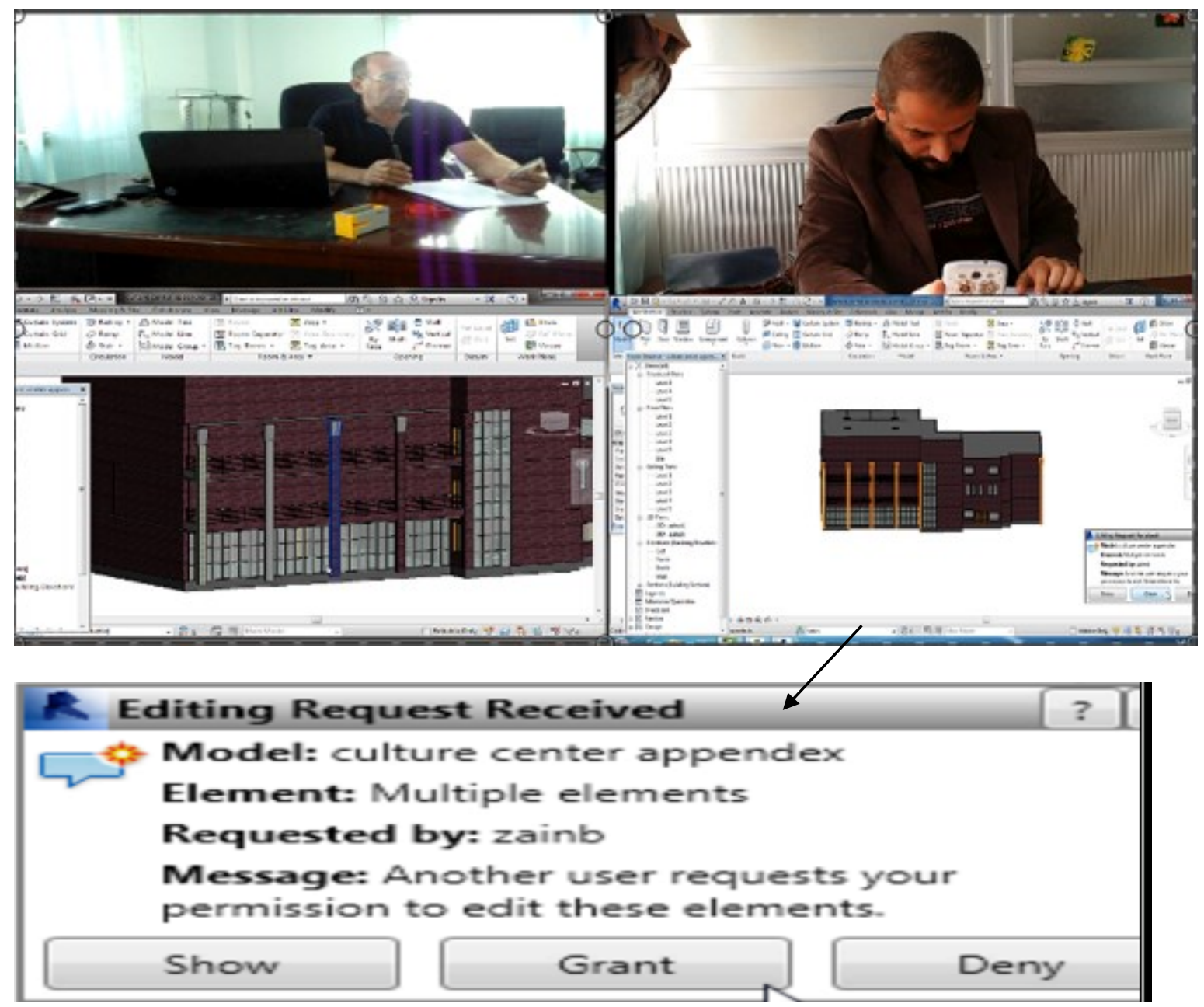

Figure (3) Show Request permission between users

For both FTF and CMC tasks, the users have to work using the 3D computer model of the building, some tasks were real or actually occurred during the execution, but some tasks were virtual and have been proposed by some engineers. The time required to complete each task was 30 minutes, it is difficult doing experiment in time less than 30 minutes because there are some design changes, also it is difficult doing experiment in time more than 30 minutes because there is a difficulty taking more than an hour from volunteers in both tasks. 


\section{Results and Discussion}

\subsection{Team Productivity and the Total Number of Work Related Words}

In a collaborative task more productivity typically requires more communication relevant to the problem [9]. The quantity of communication largely depends on the exchange of speech between people. Fig.(4) shows the relationship between team productivity and the (TNWRWs) stated by the users over time for FTF. It is obvious that the team productivity for each time intervals coordinate with the (TNOWs) as well as it can be seen that there is a strong correlation between them, as indicated in the correlation factor of 0.82 .

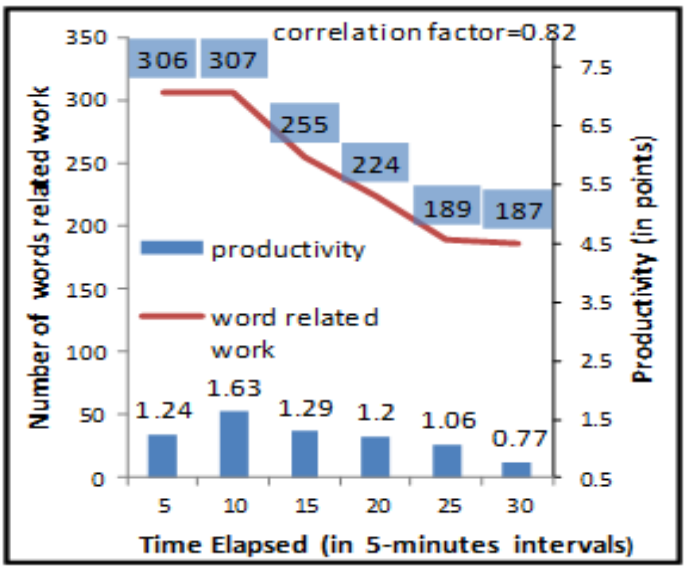

Figure(4) Team Productivity and Number of Work Related Words in FTF

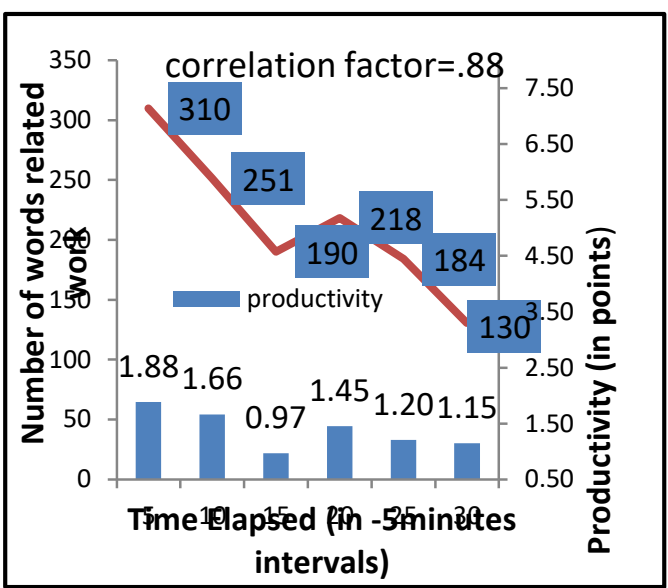

Figure(5) Team Productivity and Number of Work Related Words in CMC

For CMC as shown in Fig (5) there is a very strong correlation between team productivity and the (TNWRWs) over time, as indicated by the correlation factor of 0.88 .This possibly indicates that on CMC people concentrate more on their work. Fig.(6) Shows the relationship between the percentage of (TNWRWs) of the (TNOWs) and team productivity in FTF and CMC. Generally, there is a negative relationship (very weak correlation) between team productivity and the percentage of (TNWRWs) for FTF, the reason in this is that when the (TNOWs) is high, the proportion of the (TNWRWs) would be few (or in other words when (TNOWs) increased, the proportion (TNWRWs) increased too) in most of the experiments. In other experiments, when the proportions of the (TNOWs) are few, the (TNWRWs) would be high; While in CMC it tends to a positive relationship (weak correlation). For FTF the correlation is weaker than in $\mathrm{CMC}$, as indicated in the correlation factor of -0.3532 , while for CMC was 0.5737 . 


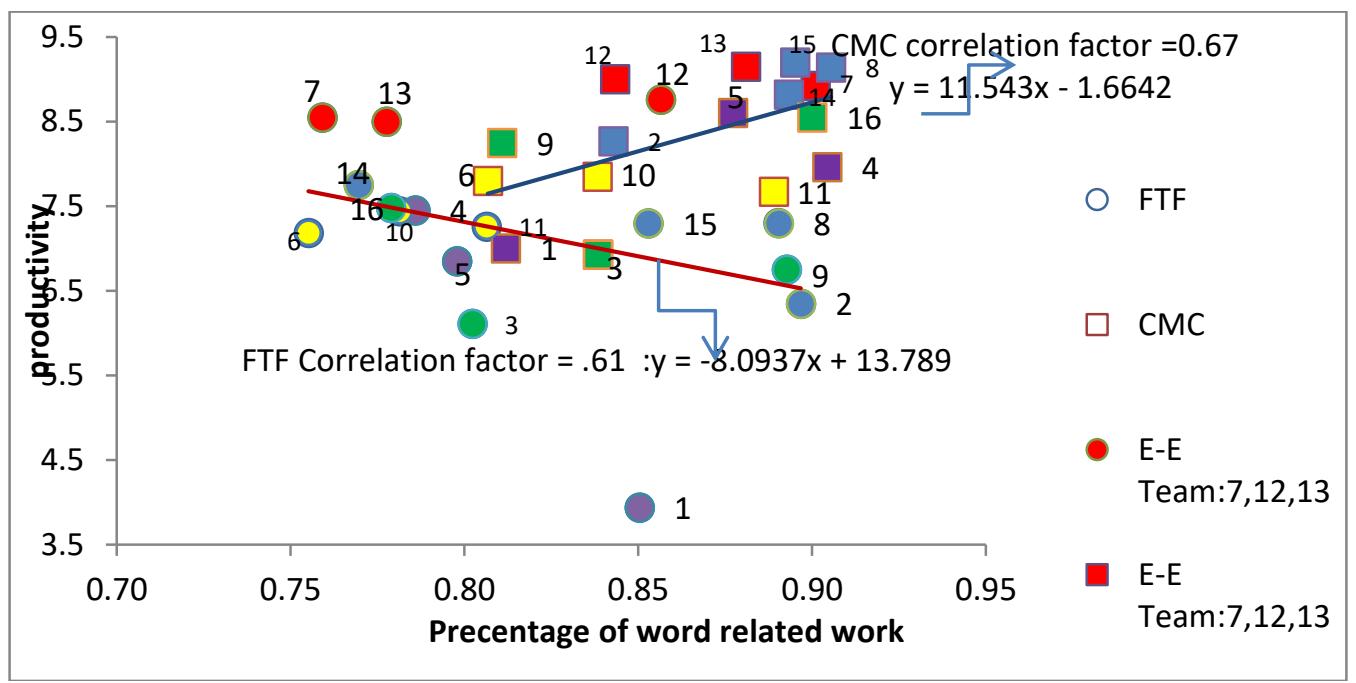

Figure (6) Percentages of Work Related Words and Team Productivity in FTF and CMC

From Fig.(6), it can be observed that, there is a relationship between the percentage of work-related words and the team type. For CMC teams type Expert-Expert and Expert-Junior expert the percentage of work related words is relatively high. However, for teams type Expert-Novice, Junior expert-Novice and Junior expert - Junior expert with a few exceptions, the results are noticeably lower. It is observed that the users in these groups spent some of their time talking about non-work related matters. While in FTF team type Expert-Expert and Junior Expert-Junior expert the percentage of work related words is relatively low ,that's because the close distance between them specially if they were familiars with each other's, or rather they're an experienced with giving high productivity with a high proportion of (TNOWs) include the proportion of (TNWRWs) and the percentage of (TNN-WRWs).

\subsection{Team Productivity and the Number of Exchanges}

The (NOE) has been defined as a measure of the collaboration between the team members through specific time. Collaboration degree is one of the most important factor which should be considered during the assessing of the team performance in FTF and CMC [18]. The productivity of each team is a very important indicator for any commercial process and in a collaborative work this can be anticipated to be influenced by the interaction between team members. This section therefore considers the relationship between team productivity and the number of exchanges between two users in FTF and CMC. Figures (7 and 8) demonstrate the relationship between team productivity and the number of exchanges in FTF and CMC over time respectively. It can be seen that there is a strong positive correlation between them as indicated by the correlation factor of 0.966 for FTF and 0.989 for CMC. During all "time intervals" the 
trend of the curve is identical to the histogram (i.e. team Productivity increases when the number of exchanges increases).

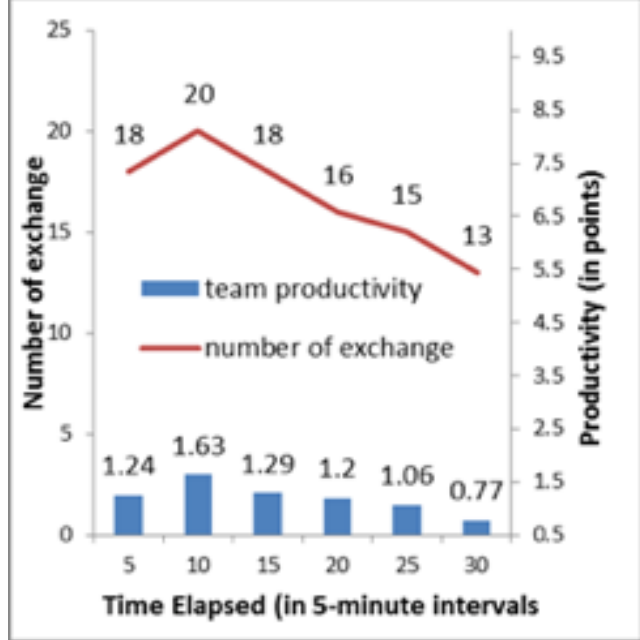

Figure(7) Team Productivity and Number of Exchanges in FTF

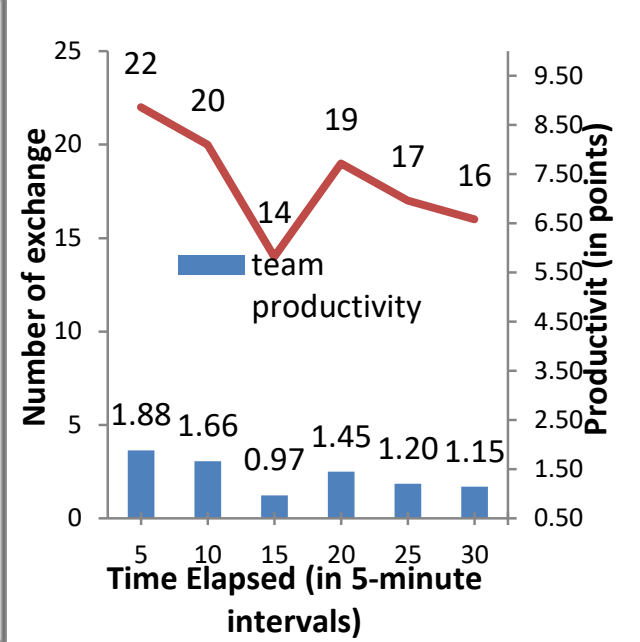

Figure(8) Team Productivity and Number of Exchanges in CMC

In Fig.(9), it can be observed that there is a relationship between the (NOE) and the team type, As can be seen teams type Expert-Expert and expert - Junior expert relatively are high . However, for teams type Expert-Novice, Junior expert-Novice and Junior expert - Junior expert are with a few exceptions, the results are noticeably lower. It is observed that the users in these groups are low interacted between them .While in FTF team type Expert-Expert and Junior Expert-Junior expert the number of exchange is relatively high, that because of the close distance between them specially if they are familiar with each other's as mention before and also the close experience level between them. 


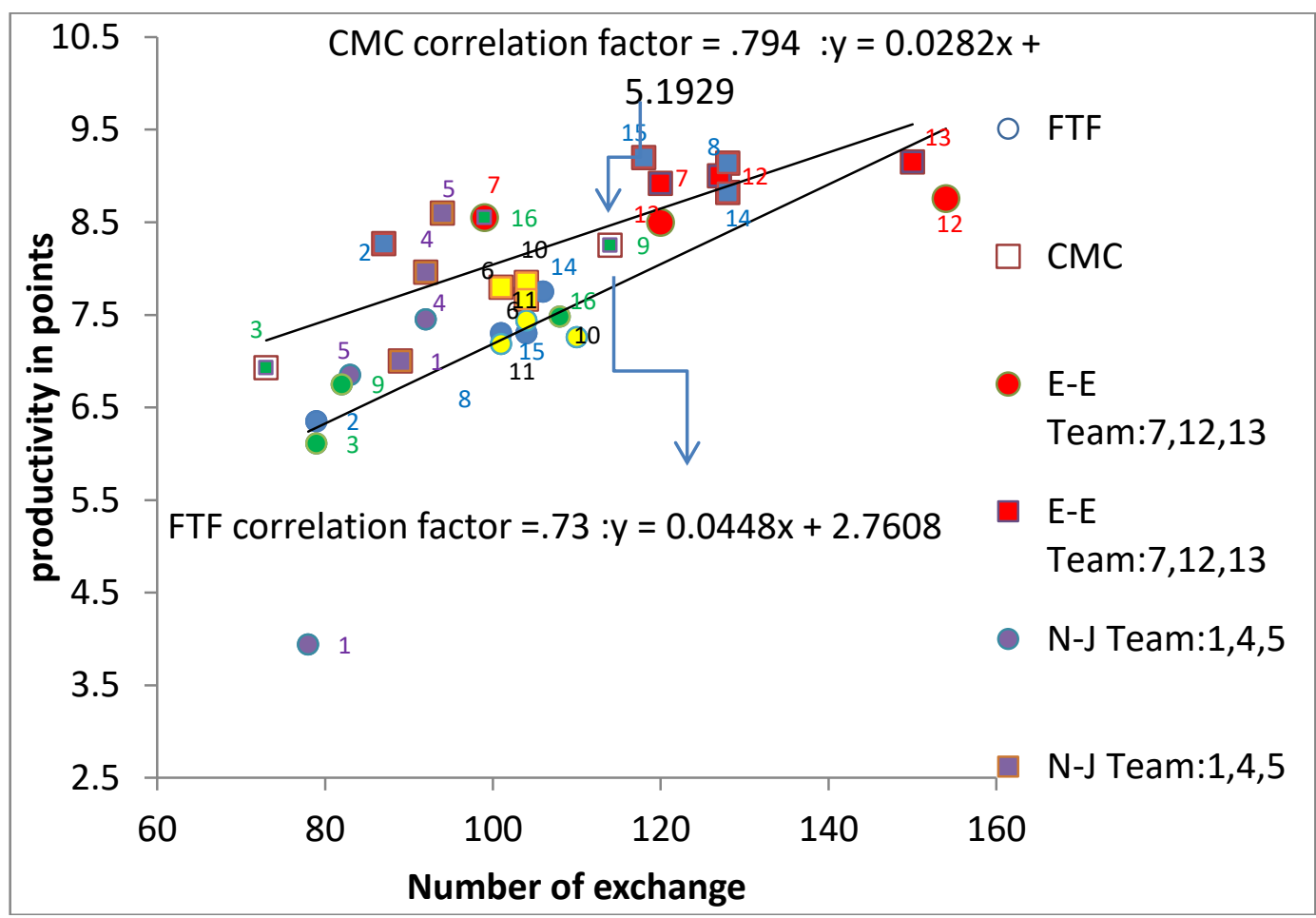

Figure(9) Team Productivity and the Number of Exchanges in FTF and CMC

The number of exchanges in CMC is higher than in FTF for $56.25 \%$ of the total experiments while the (NOE) in FTF was higher than in CMC for $18.75 \%$ of the total experiments, these were equal in experiment $4,6,7,10$ which represents $25 \%$ of the total.

\subsection{Team Productivity and Working Time in FTF and CMC}

Working time indicates the time spent by every team during the overall duration of the experiment (i.e. 30 minutes) doing productive work. Working time in CMC is higher than in FTF in each time interval. Also, as previously indicated, the total productivity in CMC is higher than in FTF. This section studies in more details the relationship between the working time and team productivity in each time interval. Fig.(10) shows the relationship between team productivity and working time in FTF. It is clear that there is a strong positive correlation between them, as indicated by the correlation factor of 0.8932. For CMC, as shown in Fig.( 11), it is obvious that there is a moderated positive correlation between team productivity and working time in each time interval, as indicated by the correlation factor of 0.7579 . 


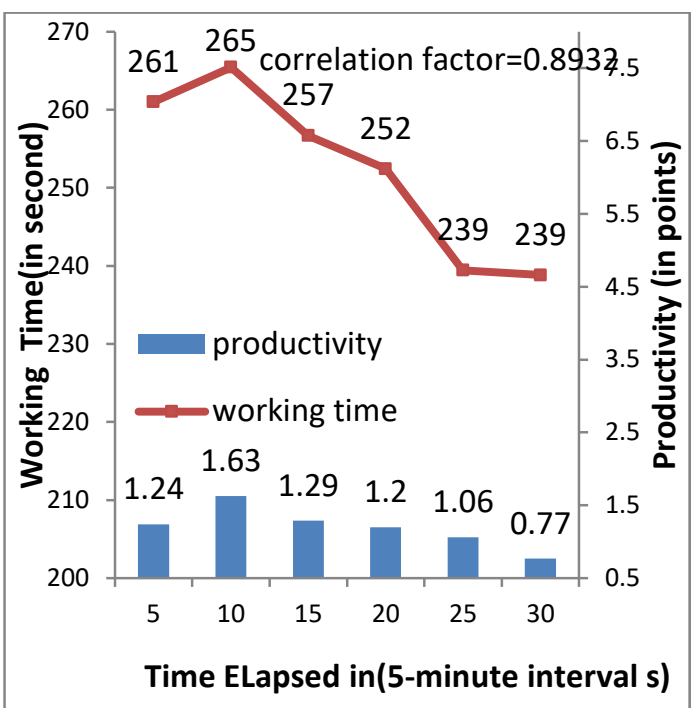

Figure(10): Team Productivity and Working Time in FTF

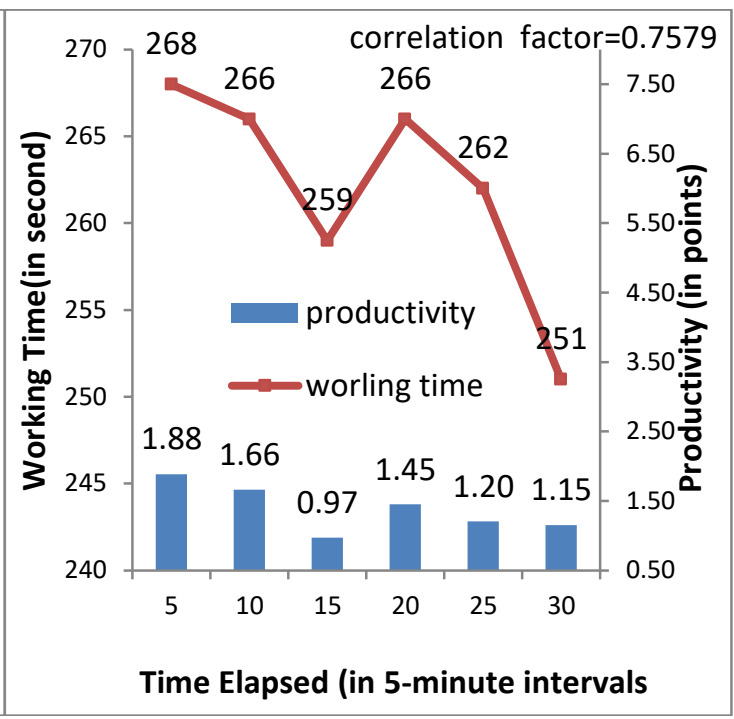

Figure(11): Team Productivity and Working Time in $\mathrm{CMC}$

Fig.(12) explains the direct (i.e. not in relation to time intervals) relationship between working time and team productivity for FTF and CMC in all the 16 experiments. Generally, it is clear that there is a moderated positive correlation between team productivity and working time in two methods, as indicated by the correlation factors of 0.73 for FTF and 0.76 for CMC, in addition to that the slopes of the two bestfit straight lines are nearly equal in two cases, this means that team productivity is affected by working time in same degree in both methods of communication. Working time for $\mathrm{CMC}$ is higher than $\mathrm{FTF}$ in $68.75 \%$ of the total number of experiments, while FTF is higher than CMC in $18.75 \%$ and working time in FTF is equal to CMC in 5, 11 experiment in $12.5 \%$. 


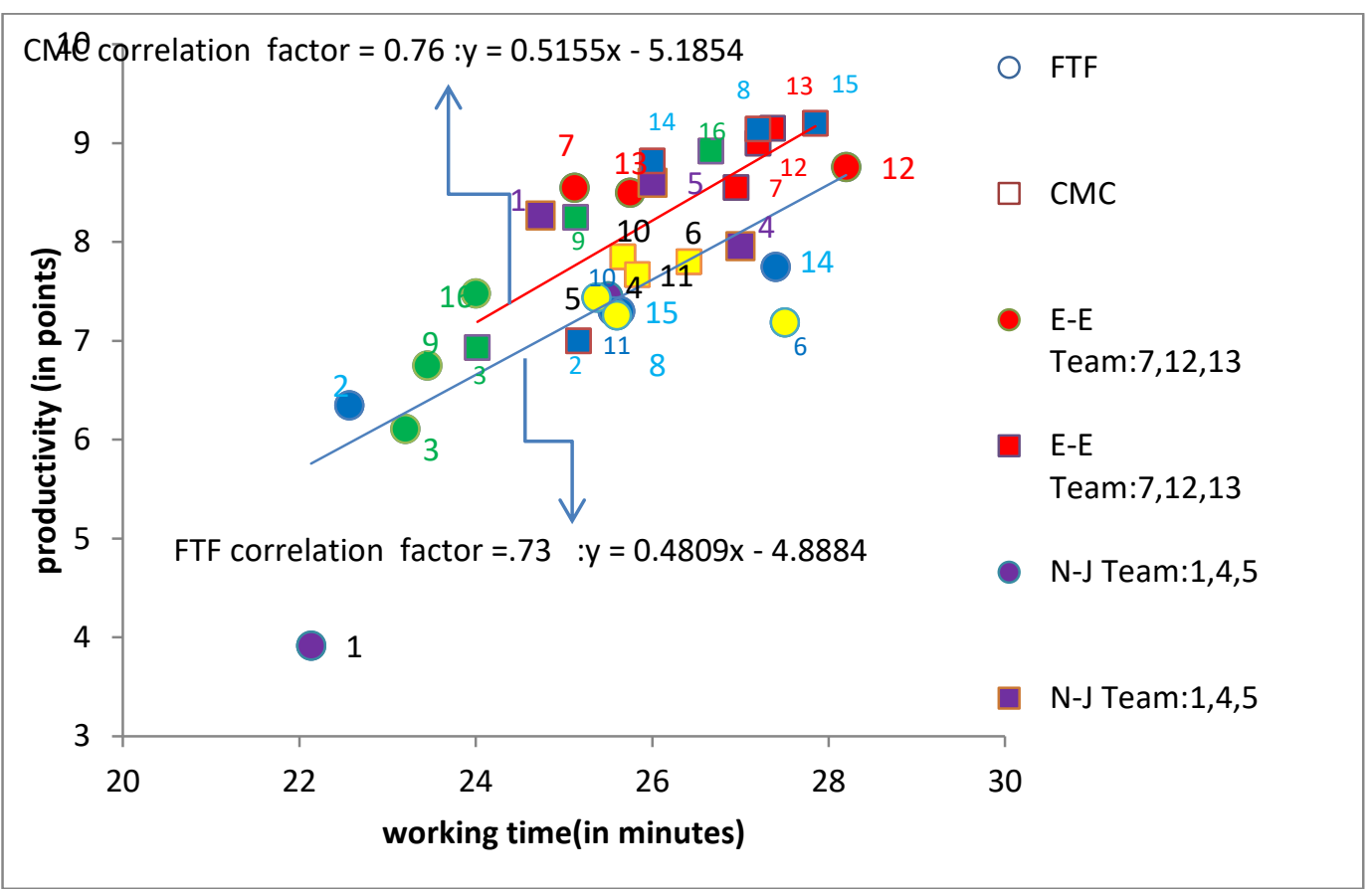

Figure(12)Team Productivity and Working Time in FTF and CMC

\subsection{Team Productivity and Wasted Time in FTF and CMC}

Wasted time is defined as the time which is spent on non-work related words, The wasted time for FTF is higher than in CMC in each time interval+. This section discusses the relationship between wasted time and team productivity with respect to time. For FTF, Fig (13) shows the relationship between team productivity and wasted time. It can be seen that there is a strong negative correlation, as indicated by the correlation factor of -0.8356 . For CMC, as can be seen in Fig (14), there is a weak negative correlation between the two aspects, as indicated by the correlation factor of 0.3416. This value of the correlation factor shows that productivity has a relationship with wasted time in FTF stronger than in CMC. 


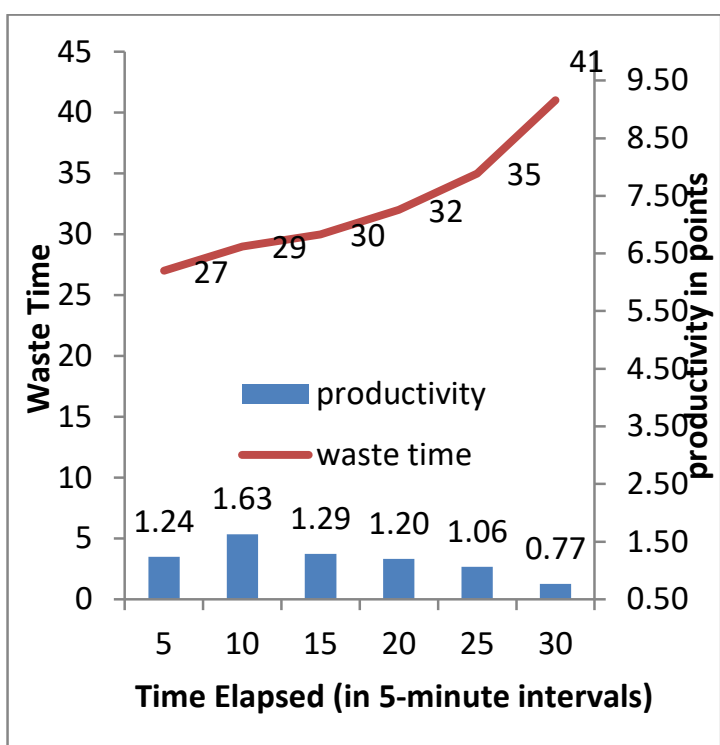

Figure (13)Team Productivity and Wasted Time in FTF

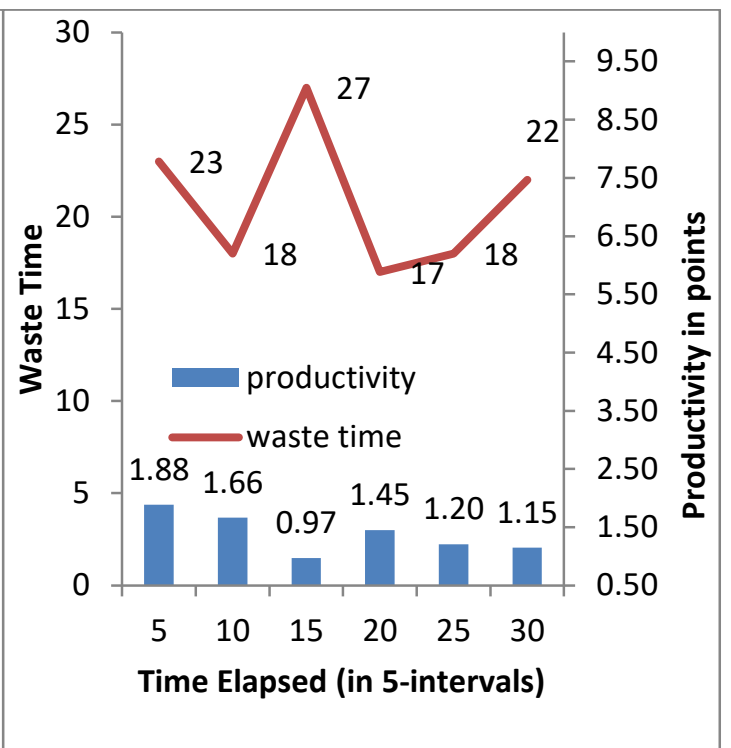

Figure( 14)Team Productivity and Wasted Time in $\mathrm{CMC}$

Fig.(15) shows the overall relationship between wasted time and team productivity in FTF and CMC, for each of them all the 16 experiments. Generally, there is a strong negative correlation in FTF and Moderate negative correlation in CMC between team productivity and wasted time, as indicated by the correlation factors of - 0.9 for FTF and - 0.61 for CMC. This means that the effect of wasted time on team productivity in FTF is more than in CMC. As one would expect, if wasted time increases, team productivity would decrease and vice versa. Wasted time in FTF amounts to more than the wasted time in CMC in $81.25 \%$ of the total number of experiments. There is also a relationship between the team experience level and wasted time as clearly the wasted time for a team type Expert-Novice in FTF and Team type Novice-Junior expert in CMC are more than those for teams type Expert-Expert, Expert-Junior expert and Junior expert - Junior expert . Also, it is clear that Teams 3 in FTF and CMC has the greatest wasted time; this could be because those users have a prior relationship (and thus, they got the highest (TNN-WRWs)). 


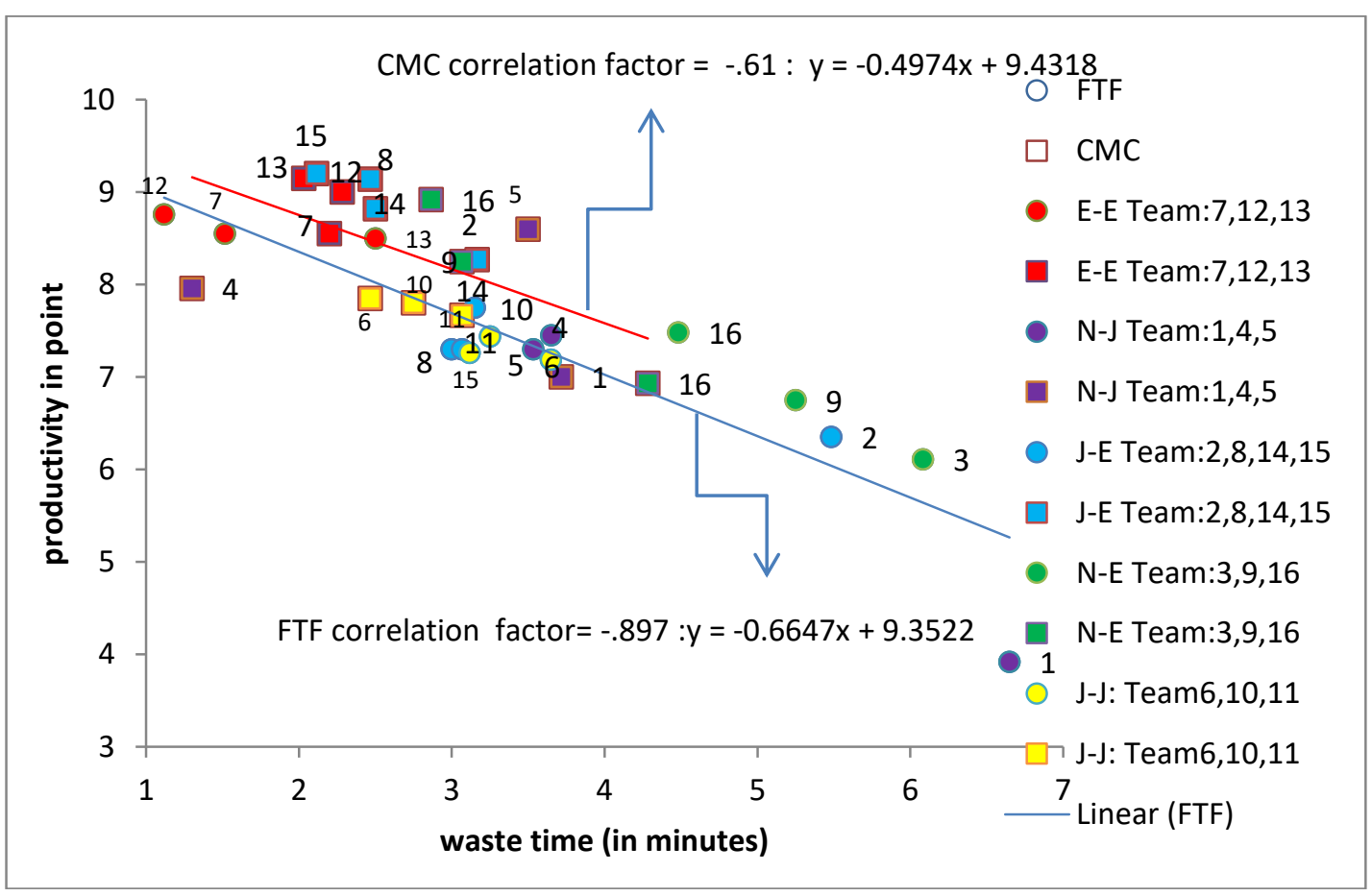

Figure (15) Relationship between Wasted Time and Team Productivity In FTF And $\mathrm{CMC}$

\section{Conclusions}

\section{1 .Team Productivity and the (TNWRWs)}

There is a very strong correlation between team productivity and the (TNWRWs) for each time intervals; Correlation factor indicated in FTF was 0.82 and 0.88 in CMC. This possibly indicates that in CMC people were more concentrating on their work.

Also, there is the relationship between the percentage of work related words of the (TNOW) and team productivity in FTF and CMC. Generally, there is a negative relationship (weak correlation) between team productivity and the percentage of (TNWRW) in FTF, the reason is that when the (TNOW) is increased, the proportion (TNNWRWs) would increase too and the proportion of the (TNWRWs) would be decreased. While in CMC it tends to a positive relationship (moderate). In FTF, the correlation factor was -0.3532 , while it was in $0.5737 \mathrm{CMC}$.

\subsection{Team Productivity and the Number of Exchanges}

Team Productivity increases when the number of exchanges do, where there is a very strong positive correlation between them as indicated by the correlation factor of 0.966 in FTF and 0.989 in CMC. 


\subsection{Team Productivity and Working Time in FTF and CMC}

There is a relationship between team productivity and working time in each time interval, there is a very strong positive correlation between them, as indicated by the correlation factor of 0.8932 in FTF and strong positive correlation 0.7579 in CMC. Also, there is a relationship between working time and team productivity in both FTF and $\mathrm{CMC}$ in all the 16 experiments. It was clear that there is a strong positive correlation between team productivity and working time in two methods, as indicated by the correlation factors of 0.73 in FTF and 0.76 in $\mathrm{CMC}$, this means that team productivity was affected by working time in both methods of communication closely.

\subsection{Team Productivity and Wasted Time in FTF and CMC}

There is a strong negative correlation, as indicated by the correlation factor of 0.8356 in $\mathrm{CMC}$ for each time intervals, but weak negative correlation was indicated by the correlation factor of -0.3416 in FTF. Also, there is a relationship between wasted time and team productivity in FTF and in $\mathrm{CMC}$ for 16 experiments, It was a very strong negative correlation in FTF and strong negative correlation in CMC between team productivity and wasted time, as indicated by the correlation factors of -0.9 in FTF and -0.61 in CMC.

\subsection{Effect team experience level on communication and collaboration}

There is a strong positive relationship between the percentage of work-related words and the team experience level, as indicated by the correlation factor of 0.67 in CMC and 0.61 strong negative relationships in FTF. There is a strong relationship between the number of exchanges and the team experience level, as indicated by the correlation factor of 0.794 in CMC and 0.73 in FTF. 


\section{References}

1- De'Mico Davis, C. E. S., Kunsal, T., Pickering, J., \& Svoboda, K (2012), Gender, Extraversion, and Team Cohesion.

2- Borcherding, J. D. (2008), "Construction Productivity", Course Package, School of Civil, Architectural, and Environmental Engineering, the University of Texas at Austin, Austin, TX.

3- Hewage, K. N. and Ruwanpura, Y. J. (2009), "A novel solution for construction onsite communication - the information booth", Canadian Journal of Civil Engineering, 36(4), 659-671.

4- Chan, A. P., Ho, D. C., \& Tam, C. M. (2001). Effect of interorganizational teamwork on project outcome, Journal of Management in Engineering, 17(1), 34-40.

5- -Lawler, E.E., Mohrman, S.A., and Ledford, G.E. (1995). Creating high performance organizations: practices and results of employee involvement and Total Quality Management in Fortune 1000 companies, Jossey Bass Business and Management Series, 186.

6- Cohen, S.G., and Bailey, D.E. (1997)."What Makes Teams Work: Group Effectiveness Research from the Shop Floor to the Executive Suite." Journal of Management, 23(3), 239- 290.

7- Martin, A., \& Bal, V. (2006). The state of teams. Greensboro, NC: Center for Creative Leadership.

8- Kerma, V.K. (1997), Managing the Project Team, the Human Aspects of Project, Volume Three.

9- Hatem, W. A. (2012). Comparing the effectiveness of face to face and computer mediated collaboration in design, (Doctoral dissertation, Cardiff University United Kingdom).

10-Dylkiewicz, P. and Knudsen, K. (2010). The Productivity of Multicultural Teams: What Is the Influence of National Cultural Diversity. Aarhus School of Business. Aarhus University. http://pure.au.dk/portal-asb-student/files/10329/FINAL_THESIS.pdf.

11- Adler, N. J., \& Gundersen, A. (2007). International dimensions of organizational behavior. Cengage Learning.

12-Kabirifar1a, k. A. M. Y. A. R., \& Ghafourian, k. (2014). Time implication and measurement in construction industry. Indian j. Sci. Res, 4(5), 366-374.

13- International labour organization (2008), Measurement of working time, Report II, 18th International Conference of Labour Statisticians. 
14- Kalsaas, B. T. (2010). Work-time waste in construction, In Proceedings of the 18th Annual Conference of the IGLC, Technion, Haifa, Israel.

15- Ean L. Cheng (2010) ,Face-to-face Versus Computer-mediated Communication: Exploring Employees' Preference of Effective Employee Communication Channel, International Journal For The Advancement Of Science \& Arts, VOL. 1, NO. 2.

16- Martins L.L. , Gilson L.L., and Maynard T.M. (2004), Virtual teams: What do we know and where do we go from here? Journal of Management, 30(6), PP 805-835.

17-Leenders, R.T.A.J., J.M.L.V. Engelen and J. Kratzer (2003), Virtuality, communication, and new product team creativity: a social network perspective. Journal of Engineering and Technology Management, 20: 69-92.

18-Kaushik, R., David, P., Kline, S. \& Oaks, D., (2000). Social presence effect: A study of CMC versus FTF in collaboration fiction project. In: Proceeding of the 5th Annual tional Workshop, Universidad Fernando Pessoa, 9-11 October Porto, Portugal, pp. 1-28. 